\title{
A genre-pragmatic analysis of Arabic academic book reviews (ArBRs)
}

\author{
Mohammed Nahar Al-Ali \\ Jordan University of Science and Technology
}

This study aims to investigate the rhetorical genre components and the pragmatic evaluation options used to articulate the communicative function of ArBR genre, and find out how these generic and evaluation options contrast with those reported in other languages and cultures. To this end, a corpus of 50 book reviews written by 50 Arab reviewers was collected and analyzed within the rhetorical components developed and applied by Motta-Roth (1998) to English book reviews. The present study drew on Hyland (2000), Gea Valor (2000-2001), Moreno and Suárez (2008a) and Alcaraz-Ariza (2010) in order to examine how the qualities of ArBRs are evaluated and in which terms (i.e., criticism or praise). The results indicated that the Arab reviewers employed additional sub-moves that have not been used by other researchers. Unlike English book reviewers, Arab reviewers try to avoid criticism. Instead, they usually devote most of their book reviews to describe and summarize uncritically although critical appraisal is supposed to be the backbone of this genre. These purposive generic component preferences and evaluation tendencies can be explained with reference to the goal of the academic community and the writing culture that constrain Arab reviewers' academic behavior. I hope that the results of this study will provide graduate students and novice researchers with further awareness of the acceptable generic strategies, the linguistic choices and pragmatic evaluative options that can be used to write an evaluation of a piece of research.

Keywords: genre, academic discourse, book review, Arabic

\section{Introduction}

A book review (BR) is an academic practice, the purpose of which is to introduce and evaluate newly published books in a particular academic culture (Gea Valor 2000; Hyland 2000). In Vandenbroucke and de Craen's (2001) view, BRs play a significant role in refining scientific knowledge and encouraging research. They 
provide a forum for the academics of the interdisciplinary community to evaluate their peers' research (Hyland 2000). However, the BR is thought of as an 'intermediate genre with a marginal status' (Felber 2002, 68) due to its limitations as a reference text (Salager-Meyer et al. 2007), especially when compared to the research article as an academic genre.

In the academic culture described by Hyland and Gea Valor, a BR has two main purposes: descriptive-informative and evaluative, which in turn reflect the two basic functions of language: the ideational function (Halliday 1994) where writers provide an informative description of the book reviewed and the interpersonal function where the book reviewers articulate their evaluative opinion including 'praising comments and their criticism and suggestions for improvement' (Gea Valor 2000, 25). The evaluative function is a primary one in this process as it involves the assessment of a colleague's work; it refers to 'the speaker or writer's attitude, or stance towards, viewpoint on, or feelings about the qualities that he or she is talking about' (Thompson and Hunston 2000, 5). Since reviews are centrally evaluative, Hyland $(2000,41)$ thinks that they carry interpersonal relation conflict as the colleague's work is seen 'in its most nakedly normative role, where it publicly sets out to establish, assess merit and, indirectly, evaluate reputations. This emphasizes that BRs cause a kind of face threat (Brown and Levinson 1987) and may undermine interpersonal relationships between the book writers and reviewers. The communicative purposes mentioned above constrain the content and formal schematic structure of the BRs. The readers and writers are thus strongly influenced by their assumptions about the generic components, language resources and functions used to evaluate and structure the content and form of the BR.

However, cross-cultural studies have reported many aspects of variations in the rhetorical structure and communicative purpose of this genre cross-culturally (e.g., Suárez and Moreno 2008) and in the distribution of positive and negative evaluative acts (e.g., Lores-Sanz 2012) as well as in the rhetoric of criticism (e.g., Salager-Meyer et al. 2003). Such intercultural divergences can be accounted for in terms of the socio-cultural and academic context giving rise to this genre. Thus, in creating the review, the writer aligns him/herself with the socio-cultural and academic assumptions related to a particular genre to reproduce these cultural and academic conventions. Taking this into account, this piece of research focuses on what evaluative and generic preferences Arab book reviewers employ to construct their reviews and how these preferences contrast with those reported in other academic cultures, and the socio-cultural and academic motivations that have given rise to these strategic options. 


\section{Literature review}

Book reviews have been the subject of various studies in different contexts during the past three decades. Most of these studies have mainly focused on the generic structure of academic reviews (e.g., Motta-Roth 1998; Nicolaisen 2002; Hartley 2006; Suárez and Moreno 2008) and the evaluative language and evaluation strategies related to praise and criticism (e.g., Belcher 1995; Gea Valor 2000; Hyland 2000; Alcaraz-Ariza 2010). Other studies have explored this genre in non-academic contexts. For example, Gea-Valor (2014) shed some light on reviews of fiction, examining how reviewers construct their identity and that of their readers as well as the nature of the relationship between the reviewer and the reader by making use of the metadiscoursal features related to attribution and engagement markers.

Regarding the research related to the rhetorical components of BRs, Motta-Roth (1998) analyzed 180 BRs in Chemistry, Economics, and Linguistics. The researcher found that the rhetorical organization of academic BRs corresponds to four moves: (i) Introducing the Book, (ii) Outlining the book, (iii) Highlighting parts of the book, and (iv) Providing evaluation of the book. Each of these moves, in turn, comprises one or more sub-moves or steps. Nicolaisen (2002) found that Motta-Roth's model is identified in over $80 \%$ of 60 BRs examined. Likewise, Hartley's (2006) study of the features of BRs revealed results that are remarkably in line with the points made by Motta-Roth's (1998) and Nicolaisen's (2002) who both reported that BRs share main components irrespective of the discipline they belong to. However, Hartley reported a few disciplinary differences. Similarly, Suárez and Moreno (2008) found that although literary book reviews in English and Spanish share similar rhetorical structural patterns, Spanish texts develop more descriptive informative sub-functions.

Regarding evaluation and evaluative language used in BRs, Hunston (1993: 58) defines evaluation as 'anything which indicates the writer's attitudes to the value of an entity in the text'. The writer's attitude or judgment of good or bad is usually expressed by attitudinal lexical items qualifying the value or quality of an entity on the good-bad scale. The evaluation of value is usually indicated through lexical items expressing accuracy, consistency, usefulness reliability or importance (Stotesbury 2003, 328). Martin and White (2005) employed the 'appraisal theory', the main function of which is to help the writers express their evaluation. According to the researchers, appraisal is concerned with how the writers express their positive or negative 'attitude' toward the things in the real world. Attitude can be classified into three sub-systems: affect, which is signaled by lexical terms that express human beings' emotive reactions; judgment, which refers to human beings' positive or negative attitude toward behavior; and appreciation, which is a kind of evaluation related to things. 
Evaluation in academic reviews functions mainly to 'evaluate the scholarly work of a professional peer within the scholarly community' (Lindholm-Romantschuk $1998,40)$. A number of previous studies have examined the dimension of evaluation in academic reviews. Some researchers evaluated the qualities of BRs in different disciplinary cultures (e.g., Hyland 2000), others examined evaluative language in specific disciplinary culture (e.g., Gea Valor 2000-2001; Alcaraz-Ariza 2010), some others compared evaluation in BRs at an ethnic cultural level (Salager-Meyer et al. 2003; Salager-Meyer and Alcaraz-Ariza 2004; Suárez and Moreno 2008; Moreno and Suárez 2009; Lores-Sanz 2012), whereas others analyzed evaluative language cross-culturally (Itakura and Tsui 2011).

With respect to variations in disciplinary cultures, Hyland (2000) examined how the following qualities of the books reviewed were evaluated in the so-called 'soft' disciplines and 'hard' ones: content, style, readership, text, author and publishing. According to him, evaluation in the soft discipline BRs tends to be longer and more discursive than that in the hard ones. Besides, the reviews in the soft disciplines tend to be more critical, while praise is likely to be fulsome in both areas. The author concluded that such differences in using criticism are due to different disciplinary culture requirements. At the level of a particular disciplinary culture, Gea Valor (2000-2001) demonstrated the importance of politeness considerations in establishing and maintaining a harmonious interpersonal relationship with the reviewee. The author argued that a balance between compliments and criticism can be achieved by means of both positive and negative politeness strategies; the former function to establish solidarity with the reviewee, whereas the latter mitigate the imposition of the unavoidable effect of face threatening acts (FTAs). Likewise, Alcaraz-Ariza (2010) illustrated how the positive and negative evaluative acts are used in English medical BRs not only to lessen criticism but also to maintain social harmony. Regarding evaluative language at the level of ethnic cultures, Salager-Meyer and Alcaraz-Ariza (2004) compared negative appraisal in academic BRs published in Spanish, French and English medical journals showing that the Spanish book reviewers make more negative appraisals in their BRs than their French and English counterparts. Moreover, French and Spanish reviewers employ a lot of mitigation devices to soften their criticism, whereas English reviewers tend to make their criticism directly using few mitigation expressions. Likewise, Suárez and Moreno (2008) found that although literary BRs in English and Spanish share similar rhetorical structural patterns, Spanish texts include less criticism strategies.

Regarding evaluating academic BRs written by writers from different national cultures, the results reported by Moreno and Suárez (2008a) on a cross-cultural enquiry into Anglo-American and peninsular Spanish literary BRs showed that the Spanish writers tend to be less critical and relatively more positive when evaluating the books than their Anglo-American counterparts. In addition, Lores-Sanz 
(2012) reported divergences in the distribution of positive and negative evaluative acts in BRs selected from British and Spanish history journals. For instance, the positive acts were very frequent in Spanish BRs in comparison to negative ones. In contrast, evaluation in English reviews is distributed almost to a similar extent between both the author and the book reviewed; however, in Spanish the book is critically assessed rather than the author.

Concerning evaluation strategies in peer-reviewed texts, the reviewers were found to go through a number of strategies at the local and global levels to mitigate the amount of face threatening in order to maintain a positive relationship with the writers of the texts reviewed. For example, Johnson $(1992,65)$ reported that writers used the following three different ways to redress specific FTAs: 'good news/bad news pairing strategy', 'good news/bad news chunking strategy', through which writers pair a compliment with a string of specific FTAs, and 'a compliment-asrationale strategy, where the writer uses a compliment as a persuasive rational for a suggestion or criticism'. Besides, Johnson (1992) and Johnson and Roen (1992) illustrated how the reviewers frame their reviews at the global level with praise in order to create an appropriate solidarity framework. Likewise, Belcher (1995) thinks that evaluative language involves a high degree of 'cautious indirectness', particularly when expressing negative criticism. Therefore, in order to mitigate the force of criticism, reviewers commonly tend to preface a negative comment with a positive compliment. This in turn gives rise to the very frequent 'good news/bad news' pairing discourse pattern in the texts reviewed. Hyland (2000) also found that reviewers tend to open English BRs with praise before they offer criticism in the subsequent sections and close these reviews with a positive evaluation in order to repair the adverse effect of criticism and protect the face of the book authors. Another contrastive study was conducted by Itakura and Tsui (2011) to analyze the rhetorical strategies for providing criticism utilized in English and Japanese BRs. The authors found a frequent use of praise in English BRs in order to create solidarity. However, in addition to praise Japanese reviewers use other strategies such as apology and self-denigration, rhetorical questions, and recasting problems as potential for future research. The authors concluded that such results suggest that the frequent use of mitigated criticisms might be related to 'the prevalence of a negative politeness strategy and cultural values such as modesty, humbleness and selfishness' (p. 1378).

The literature review presented so far has revealed that evaluation in BRs has proven to be a culturally and disciplinary common practice as there are cross-cultural and cross-language differences in terms of the degree of criticism and praise as well as the type of strategies utilized to express evaluation. This in turn calls for further contrastive research in other languages and cultural contexts to identify the evaluation resources and rhetorical generic components used. Apart 
from the English, Spanish, French, and Japanese studies of BRs, little is known of the way other cultural groups express the rhetorical structure of this genre. Although the BRs are frequent in Arabic, no study, to the best of my knowledge, has been carried out on ArBRs written by Arabic native speakers. I hope that the present study will, in part, fill this gap and contribute to a better understanding of this academic genre in Arabic.

Therefore, the purpose of this study is to find out the generic structural components used to articulate the purpose of this genre, the qualities evaluated in ArBRs and how these generic and evaluation options contrast with those reported in other languages and cultures.

This analysis will hopefully reveal to what extent texts belonging to the same genre can vary in relation to language and culture in terms of rhetorical structure and evaluative discourse. Thus conducting further contrast of appraisal strategies across comparable academic texts and language cultures (Bhatia 2004) could help to cast some light on the possible difficulties encountered by novice writers and non-natives to 'create an appropriate rhetorical attitude and interactive tenor when writing in EAPs' (Moreno and Suarez 2008b, 752). I hope that this kind of research provides novice researchers with further awareness of the generic strategies as well as the linguistic and pragmatic strategies that are used when evaluating a piece of research in order to achieve a kind of communicative success in academic interaction.

\section{Analytical framework and methods}

The present study focuses on ArBR as an academic interpersonal evaluative genre. Therefore, this research drew on two interacting complementary theoretical paradigms: genre analysis and a pragmatics model of interaction that involves positive and negative evaluative acts. One theoretical framework that has proved to be useful in identifying the rhetorical strategies that shape a particular genre is move analysis (Swales 1990; Bhatia 2004). This model has been successfully extended by applying it to the analysis of British book reviews (BRs) by Motta-Roth (1998) and Gea-valor (2000). Therefore, I utilized this model but with some additions and modifications of certain component sub-moves. The component moves which appeared most frequently in this model are listed below; each of these components can be further divided into sub-moves or steps:

Move 1 Introducing the Book

Move 2 Outlining the Book

Move 3 Highlighting Parts of the Book

Move 4 Providing Evaluation of the Book 
Al-Ali (2005), Bhatia (1993) and Swales (1990) note that it is difficult to base genre analysis on formal linguistic clues because moves vary in size; a move may be expressed by one sentence or more, or by a clause or a phrase. Therefore the identification of the moves in the BRs was based on the propositional content of the text, explicit lexical signals, metadiscoursal markers, indicative phrasal expressions, and textual clues as well as the boundary heading and sub-headings of the text.

The present study drew on Hyland (2000), Gea Valor (2000-2001), Stotesbury (2003), Moreno and Suárez (2008a) and Alcaraz-Ariza (2010) in order to examine how the qualities of ArBRs are evaluated and in which terms (i.e., criticism or praise). Evaluation involves critical appraisal expressed by positive speech acts that attribute 'credit to another for some characteristic, attribute, skill, etc., which is positively valued by the writer' (Hyland 2000: 44), or criticism indicated by negative speech acts. Although evaluation plays a central role in BRs, its identification in the texts analyzed was not straightforward especially when it came to the way evaluative items or text fragments signaling evaluative acts were coded and analyzed. This is due to the lack of consensus on which lexical items are evaluative (Thetela $1997,102)$. Many researchers have argued that evaluation is not only a product of the semantic meaning of the word classes, but also of discourse fragments in the co-text provided or stretches of language beyond the sentence boundaries; that is because a single evaluative lexical item is sometimes ambiguous until supported by other preceding or following items that make the same point (see for example, Moreno and Suárez 2008a). Therefore, although most instances of evaluative acts were identified on the basis of explicit lexical resources that denoted the reviewers' positive or negative evaluation of the book, decisions about the evaluative force of some other instances depended on the immediately surrounding text (i.e. co-text) and/or the retrospective or prospective contextual metadiscourse labels (Stotesbury 2003; Moreno and Suárez 2008a; Alcaraz-Ariza 2010).

To isolate the positive and negative instances, I read each of the ArBRs and coded each semantically positive and negative evaluation attached to each quality of the BR. I counted the evaluative features in the books reviewed and classified them into positive or negative according to the following criteria that were used to qualify the presence or absence of certain qualities in the book evaluated such as content, authorship, style, text, etc.:

a. Explicit lexical choices indicating that a text fragment is a positive or negative evaluation, as can be seen in Example (1).

(1) yumkin-u taSniif-u haaða al-kitaab ka-taariix-in muSawar-in li-filiStiin wa-yumkin-u i?stibaaruh-u marjis-an Saamil-an li-a?saatiðat-i il-suluum-i l-i?jtimaasiyyah

'This book can be classified as a pictorial history of Palestine and considered as a comprehensive reference for the professors in social sciences.' 
The underlined lexical item 'comprehensive' in the example above contains evaluative meaning. This adjective encodes appreciation of one value of the book, leading us to consider this adjective as a positive evaluation of the readership of the book. Thus, Example (1) includes only one semantically positive speech act encoding a positive value of the book.

b. Semantically neutral or ambiguous text fragments that can be disambiguated (i.e. interpreted as a negative or positive appraisal) with reference to the retrospective or prospective metadiscourse lexical items in the co-text or rhetorical context in which they appear. The following examples illustrate this:

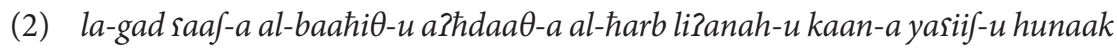
xilaal-a tilk-a al-fatrah. haaðihi itajrubat-i ilhayyah a?llatii kaanat malii?at-an

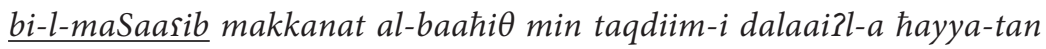
tadsam-u ra?yah-u wa-tufanid-u mazaasim-a al-a?axariin

'The researcher experienced the events of war because he was living there during that time. This live experience, which was full of difficulties, enabled the researcher to provide authentic evidence that supported his view and invalidated other's arguments.

Example (2) above includes one instance of explicit positive appraisal of the argument presented in the book reviewed encoded by 'authentic experience' and the relative clause modifying it in sentence 2 . However, if we read the underlined noun phrase and its modifying relative clause "This live experience, which was full of difficulties' in the second sentence in isolation, we may not be able to judge whether this text fragment is a negative or a positive remark. Therefore, what helps the reader to interpret this fragment is the positive evaluation, 'authentic evidence' and the relative clause modifying it in the following co-text within the second sentence. This positive appraisal can be thought of as a retrospective label that leads us to interpret the quality of the underlined fragment as positive as well. Therefore, the prospection created in the first sentence might also be thought of as one instance of praise of the author. That is because the text fragment, 'live experience', which has also been interpreted positively, is a discourse organizing anaphoric lexical item operating predictively to refer back to the first sentence. Therefore, Example (2) above includes two instances of positive evaluation encoding two values, one of which is an explicit praise of the argument as a sub-quality of the contents of the book reviewed, whereas the second is an implicit praise encoding a positive value of the author.

Likewise, in Example (3) the adjective 'controversial' can be thought of as neutral if we read the second sentence in isolation. However, the negative adjective 'difficult' in the first sentence acts as a prospective metadiscourse label that leads 
the reader to interpret the apparently neutral adjective in the second sentence as a negative critical act since it provides justification why it is difficult to follow the argument.

(3) min aS-Sasb-i naws-an maa sala al-qari?-i a?n yatatabas-a an-niqaaf-a al-masruuD-a fi haaða al-kitaab. haaða li?annah-uu yahtawii salaa masaairl-a jadalyya-tin sadiidah

'It is somewhat difficult for the reader to follow the argument presented in this book. That is because it includes many controversial issues.'

Since the BR is a highly face threatening act because the colleague's work is seen 'in its most nakedly normative role' Hyland $(2000,41)$, the study also drew on Johnson (1992), Johnson and Roen (1992) and Hyland (2000) to investigate the type of evaluative mitigation strategies used in order to maintain a positive relationship with the writers. The reviewers attempt to utilize certain evaluative mitigation strategies to delicately balance their praising comments against their criticism and suggestions (Johnson 1992; Gea Valor 2000). Such strategies include 'good news/ bad news pairing strategy' consisting of Compliment+ Criticism, 'good news/bad news chunking strategy', through which writers pair a compliment with a string of more than one criticism and suggestion or reason, and 'a compliment-as-rationale' strategy, where the writer uses a compliment as a persuasive rational for a suggestion or criticism.

\section{The corpus}

Since differences have been found between hard and soft disciplines in the linguistic choices utilized by reviewers to evaluate books (Hyland 2000, 51), the sample collected was restricted to BRs published recently in humanities and social sciences. I analyzed fifty full-length academic BRs drawn from 13 academic refereed journals written in Arabic by Arabic native speakers (see Appendix 1 for the list of the Arabic journals from which the review texts were drawn. For lack of space, the list of the BR texts is not provided here).

This choice of journals in terms of subject and number aimed to cover different branches of the disciplines and to have a manageable sample as these reviews were subjected to manual analysis. The size of the corpus amounts to 21,382 words. The average length of the texts selected ranges from 600- 2250 words. All the BRs collected were in paper-written format. 


\section{Data analysis}

The analysis of the BRs drew on two interacting complimentary paradigms: genre analysis and pragmatic evaluation analysis. The genre analysis focused on identifying what type of moves and sub-moves Arab writers utilized to articulate this genre, whereas the pragmatic analysis examined the qualities of the books reviewed and in which terms as well as the evaluative language and strategies used to qualify them.

The analysis of the BR texts revealed that Arab reviewers tended to utilize four component moves each of which included constituent sub-moves to structure ArBRs, as shown in Table 1.

Table 1. Frequency of rhetorical moves and sub-moves in the Arabic corpus

Rhetorical moves \& their sub-moves

Book Reviews (50)

\section{Introducing the book}

1.1. Stating the general purpose

1.2. Informing about the readership

1.3. Informing about the author

1.4. Indicating a gap in the filed

2. Describing the book

2.1. Providing general view of the organization of the book

2.2. Stating the topic of each chapter

2.3. Providing a summary of each chapter or of the general topic

2.4. Citing extra-text material

3. Evaluating

4. Closing

4.1. Recommending the book

4.2. Recommending the book despite the shortcomings

4.3. Providing a concluding neutral summary

4.4. Instantiating further similar research

4.5. Making supplications for the author

n $\%$

$\%$

42

10

$84 \%$

$20 \%$

$20 \quad 40 \%$

$10 \quad 20 \%$

$36 \quad 72 \%$

$18 \quad 36 \%$

$40 \quad 80 \%$

$24 \quad 48 \%$

$26 \quad 52 \%$

$17 \quad 34 \%$

$12 \quad 24 \%$

$6 \quad 12 \%$

$6 \quad 12 \%$
$9 \quad 18 \%$

What follows is the manifestation of these functional moves and the sub-moves realizing each.

\subsection{Introducing the book}

The reviewers tend to open this section by stating the general purpose of the book, using purposive statements containing lexical items, such as, yahdif (meaning 'aim') to state the purpose explicitly as it is shown in Example (4); the purposive lexical 
signals are written in bold. This component step features the highest frequency (84\%). However, the reviewers in $20 \%$ of their reviews refer to a gap or some limitation in current disciplinary knowledge before stating the aim of the book, in order to fill such a gap. This is usually indicated by using adversative conjunctives such as wa-masa ðalik (however), or lexical items like saddi il-faraay (filling a gap) as indicated in Example (5):

(4) yahdif-u Pal-kitaab-u li-tawDiih-i Pal-aaAaar-i il-Piijaabiya-ti wa-salbiya-ti lil-PistiOmaaraat-i l-2ajnabiya-ti Pal-mubaafira-ti fi i-ddiwal Ralislaamiya-ti fii Duu-i irl-iqtiSaad-i l-islaamiy

'The book aims to explicate the direct positive and negative effects of the foreign investments in Islamic countries in light of the Islamic businesses.'

(5) walaa yaraabat-a ?n yastaqbil-a Pal-qurra-?u haað al-kitaab-a ?a ћsan-a Pistiqbaal ?ið sadda faraay-an fi Pal-maktabat-i Pal-sarabiyyat-i taalamaa Sakaa minhu al-baahuun

'Unsurprisingly, this book received a warm welcome by the readers since it fills a gap in the Arabic library that has been complained of a lot by the researchers'.

Other strategic components included in this introductory move are providing information about the author of the book (40\%), and the potential readership (20\%). The former sub-move is related to the author's general qualities including his/her professional and academic qualifications, research competence and publications. The following example illustrates this quality by making use of positive adjectives or superlative ones followed by metadiscoursal markers such as baahit-un mutamaiyyiz (a distinguished researcher), and wa-huwa min xiirat-i il-baahitiin (He is one of best researchers):

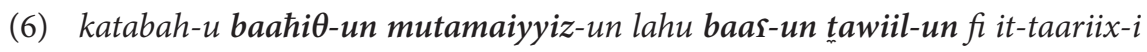

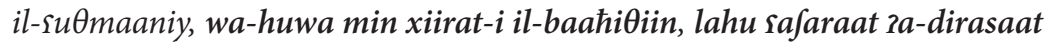
'This book was written by a distinguished researcher who has a long experience in the Ottoman history and is one of the best researchers. He has published tenths of studies.'

The potential readership component includes information related to the usefulness of this new publication for the prospective readers, scholars and discipline and in what sense. Metadiscoursal markers are used to emphasize the usefulness of this book to the discipline such as PiDafat-an jaiydat-an Pilaa maktabat-i il- Ridaarat- $i$ (a good contribution to the Administration Library), as is shown in the following example: 
(7) yusadd-u haaða al-kitaab riDafat-an jaiydat-an rilaa maktabat-i il- ridaarat-i. kamaa yahtal-u makaanat-an silmiyyat-an haamat-an naðr-an liqilat-i al-kutub-i fi haaða al-majaal fi l-saalam-i il-sarabiyy

'This book is considered a good contribution to the Administration Library; it has a very important scientific rank due to the dearth of the books dealing with such topics in the Arab World.'

\subsection{Describing the book}

In this move, the reviewer provides a general view of the book structure in terms of the chapters, parts or sections constituting it (72\%), the general topic dealt with in each section (36\%), a summary of the general topic or of each chapter (80\%), and information about the tables, references, pictures, indexes, etc. (48\%).

A thorough analysis of this move has shown that the reviewers tend to initiate this move with a signposting sub-move indicating the number of chapters or sections that make up the book (72\%) through the use of metadiscoursal markers that indicate the number of chapters into which the book has been divided (e.g., yatakawan-u ?al - kitaab-u min ?arbasat-i fiSuul 'The book consists of four chapters'). The second following step designates the title or topic of each section or chapter (36\%) with metadiscourse markers such as Pal-Pawal mafhuum Pal-Pistïmaar... wa-Aaaniy bi... (The first deals with the concept of investment... and the second with...). Example (8) illustrates these two steps:

(8) yatakawan-u Pal - kitaab-u min rarbasat-i fiSuul ka-ttaaliy, zal-2awal maf-

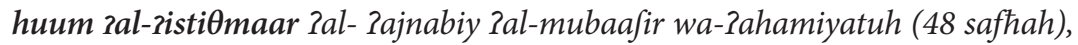

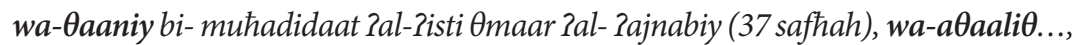
wa-2axiir-an...(59 saftah)

'The book consists of four chapters as follows: The first deals with the concept of direct foreign investment and its importance (48 pages), and the second with the constraints of foreign investment (S37 pages); the third..., and lastly,...(59 pages).'

The third sub-move is 'Providing a summary of each chapter or of the general topic' (80\%). For example, the reviewers take the chapters mentioned in Example (8) above in turn and present a summary of the general topic of each chapter in sequence to inform the readers about the propositional content of the book reviewed. It was found that $70 \%$ of the BRs is devoted to fulfill this function. This tendency leads to the conclusion that Arab reviewers tend to focus on giving information and place emphasis on telling the readers what factual content is included.

The fourth step informs about the extra-text material such as diagrams, graphs, and tables by making use of metadiscourse markers such as the ones written in bold type in Example (9). 
(9) yaftamil-u il-kitaab-u salaa sitat-i fuSuul-in bil-iDaafat-i Tila al-muqadimat-i

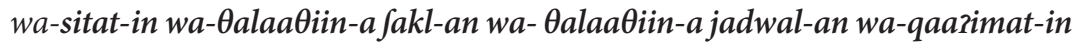
lil-maraajis-i il-sarabiyyat-i wa- 2al- 2ajnabiyat-i wa-fahaaris-in li-muhtawayaat-i il-kitaab-i wa-l-jadaawil-i wa-l-rafkaal

'In addition to the six chapters and introduction, the book includes 36 figures, 39 tables, a list of Arabic and English references, and indexes for book contents, tables and figures.'

\subsection{Evaluating}

According to Hyland (2000, 41), BRs are 'centrally evaluative'. Hunston $(1994,197)$ points out that, 'when an item is evaluated in terms of its value, that item is effectively highlighted, that is, made more important than items which are not evaluated'. Such definition can be related to this section as it includes an overall assessment of the book reviewed, highlighting points of strength and/or points of weakness. The evaluation move tends to occur immediately after 'Describing the book'. Table 1 indicates that only $52 \%$ of the reviews are evaluated, whereas $48 \%$ of the reviews present a neutral description of the book reviewed without being evaluated. Evaluation was analyzed in terms of the qualities of the book evaluated and in which terms, on the one hand, and the strategies used to mitigate the effect of negative critical statements on the other.

\subsubsection{What is being evaluated in ArBRs and in which terms?}

The data analysis shows that the qualities evaluated in the fifty BRs are the following: (a) contents, (b) author, (c) style, (d) readership, and (e) extra-text material. Table 2 shows that there are 434 appraisal statements, $(76.5 \%)$ positive and (23.5\%) negative comments, with an average of 8.5 cases per review used to assess the presence or absence of particular criteria in the qualities evaluated. This indicates that praise significantly exceeds criticism.

Table 2. Distribution of evaluation in ArBRs

\begin{tabular}{|c|c|c|c|c|c|c|}
\hline \multirow[t]{2}{*}{ Entity evaluated } & \multicolumn{2}{|l|}{ Praise } & \multicolumn{2}{|c|}{ Criticism } & \multicolumn{2}{|l|}{ Total } \\
\hline & Number & $\%$ & Number & $\%$ & Number & $\%$ \\
\hline Contents & 80 & 18.4 & 54 & 12.4 & 134 & 30.8 \\
\hline Author & 76 & 17.5 & 0 & 0 & 76 & 17.5 \\
\hline Readership & 84 & 19.4 & 2 & 0.5 & 86 & 19.9 \\
\hline Style & 60 & 13.8 & 16 & 3.7 & 76 & 17.5 \\
\hline Textual material & 32 & 7.4 & 30 & 6.9 & 62 & 14.3 \\
\hline Total & 332 & 76.5 & 102 & 23.5 & 434 & 100 \\
\hline
\end{tabular}


Concerning the qualities evaluated, $30.8 \%$ of the appraisal addresses the content issues. The aspects of the contents praised are: argument, approach, quality, currency, objectivity, and coherence. To qualify these aspects, reviewers favor adjectives such as distinctive, objective, fruitful, scientific, valuable, up-to-date, and valuable, nouns like clarity, accuracy, adverbs such as thoroughly, and verbs like make clear, reveal, enrich to highlight the argument. Statements of praise constitute $18.4 \%$, whereas $12.4 \%$ contain criticism.

The foci of positive appraisal in Example (10) are the 'discussion of the topic' and the 'quantitative approach'; the criteria used to assess them positively are niqaaf-an silmiyy-an muӨmir-an wa-mutamaiyz-an (distinguished scientific fruitful discus-

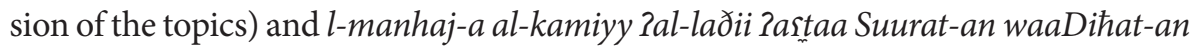
wa-daqiiqah (the clear and precise picture provided by the scientific approach).

(10) naaqaf-a al-mu?alif-u mawDuusaat-i haaða al-kitaab niqaaf-an silmiyy-an mu$\theta$ mir-an wa-mutamaiyz-an [positive speech act]... Pistaxdam-a al-baahit-u l-manhaj-a al-kamiyy zal-laðii rastaa Suurat-an waaDiћat-an wa-daqiiqah [positive speech act]

'The author provided a distinguished scientific fruitful discussion of the topics of this book [positive speech act]... The author employed the quantitative approach which gave a clear and precise picture [positive speech act].

As regards the negative evaluative acts, the main sub-qualities criticized are the argument and approach. The lexical items most often used to express criticism are adjectives such as insufficient, inconsistent and restricted, verbs like need, lack, limit, fail, overlook, and weaken and nouns such as shortcoming and weakness. The target of the negative appraisal in Example (11) is the topic; the sub-quality of the book criticized and the lexical items indicating criticism are written in bold:

(11) Pastaqid-u ?nna mawDuus-a al-farq-i bayn-a al-hukm-i iðaatiy wa-l-idaarat-i iðaatiyat-i bi-haajat-in rilaa maziid-in min al-munaaqafah... [negative speech act]

'I think the topic including the difference between self-governing and selfadministering needs further discussion... [negative speech act]'

The second most frequent quality evaluated is the readership receiving the highest proportion of praise (19.4\%), whereas criticism is almost nonexistent, with only one instance encountered. The most features evaluated are those concerning the value of the book to the reader and the discipline. The books are praised for being a significant contribution, an important reference, filling a gap, or as an intellectual and practical source to readers. It is also praised for 'rich content, multifarious evidence, saving researchers' time and efforts, and clarifying distorted issues to the readers. The following example from the corpus illustrates this: 
(12) hua 2awal-u kitaab-in yaSdur-u fi iluyat-i il-sarabiyyah wa-alaði yajsal-u min al-maSadir-i ill-su $\theta$ maaniyyat-i maadatah-u wa-sayabqaa haaða al-kitaab-u

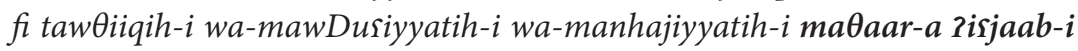
il-baaHitiin al-sarab wa-marjir-un asaasiyy-un wa-huwa ?iDafat-un mutamaiyizat-un lil-maktabat il-sarabiyyah ?alatii tusaani min naqS-in kabiir.

'It is the first book issued in Arabic whose content is based on Ottoman resources. Because of its authentication, objectivity and methodology, this book will remain a respectful source and a main significant reference for Arab researchers. It is also a significant addition to the Library which suffers a lot in this domain.'

The third quality evaluated, in terms of frequency, is the author (17.5\%). It includes the writer's competence, research abilities and research tasks carried out to write the book under review. The results show that the reviewers opt to utilize only praise to evaluate this entity, whereas criticism is nonexistent.

(13) min alwaaDiH ?anna al-muralif-a kaan-a ladiyhi il-qudrat-u sala munaaqafat-i il-mawDuus-i biTariiqat-in silmiyyat-in daqiiqat-in basda sarD-i wa- tahliil-i wujuhaat-i innaDar-i il-muxtalifah bi-Tariiqat-in silmiyyah

'It is clear that the author was able to discuss this topic scientifically and precisely after presenting and analyzing the different views objectively.'

The fourth quality evaluated is style. The reviewers comment on aspects of the writing style in terms of clarity, conciseness, organization, difficulty, readability and editorial judgements. This issue includes $17.5 \%$ of the evaluative acts; $13.8 \%$ of which express praise, whereas $3.7 \%$ carry criticism. Criticism of style is mostly ascribed to editorial blemishes and poor organization. Example (14) below illustrates positive appraisal of the style, while 15 exemplifies the negative appraisal of this issue.

(14) laqad tamm-a sarD-u kitaabah-u bi-risluub-in sahl-in wa-faiyyiq wa-sibaaraat-in jaliyyat-in yumkin-u lilqaari? istiisaabuhaa bi-suhuulah

'His book was presented in an easy and attractive style and lucid expressions that can be comprehended easily by the reader.'

(15) waaDih-un Panna taqsiim-a al-kitaab-i yattasim-u bitadaaxul-i ahdaatih-i... Pamma al-mulaahaDaat-u n-nahwiyat-u faka日iirat-un wa-muntafirat-un min muqadimat-i il-kitaab-i ilaa xaatimatih-i

'It is evident that the organization of the book lacks coherence. Regarding the syntactic errors, they are many and prevalent throughout the book.'

The fifth quality assessed is the extra-textual material, which includes the currency, number, relevance, and richness of the list of references and examples. The other textual attributes include the quality and usefulness of the non-verbal data like 
diagrams, figures, tables and pictures. These attributes are related to clarity, accuracy and adequacy of information. There is $14.3 \%$ representing this quality, almost equally divided between praise (7.4\%) and criticism (6.9\%). In Example (16), the target of positive evaluation is the bibliographic references; the criteria used to assess them are the currency, variation, richness and usefulness. The metadiscourse markers are written in bold. On the contrary, Example (17) includes criticism most of which is focused on the authors' failure to cite certain references or include quotations.

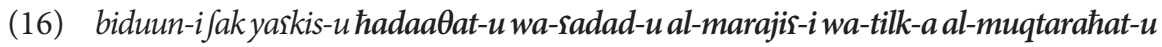
masrifat-a ilkaatib-i ilwaasisat-i wa-ZaAarat muhtawaa haaða al-kitaab 'Undoubtedly, the currency and number of references and the suggested ones reflect the author's wide knowledge and the richness of content of this book.'

(17) kaan-a almu?alif-u ahyaanan yuDamin-u basD-a al-2fkaar-i biduun-i ðikr-i maSaadiriha

'The author sometimes included few ideas without citing the source.'

\subsubsection{Mitigating criticism in ArBRs}

As stated earlier, the BR is highly face threatening because the colleague's work is seen 'in its most nakedly normative role' Hyland (2000: 41). Therefore, the negative critical statements are sometimes combined with positive strategies in order to strike a kind of balance between positive and negative evaluative acts and as a strategy to mitigate the force of criticism and establish a harmonious relationship with the reviewee by delicately balancing their praising comments against their criticism and suggestions (Gea Valor 2000: 57).

As shown in Table 2, there are 102 negative comments (23.5\%). The negative appraisal is mainly encountered in the content, textual material and style of the books reviewed. I identified four specific redressive strategic pairing options that the book reviewers resort to in order to mitigate the effect of negative comments: Compliment+ Criticism, Compliment+ Criticism + Suggestion $(\mathrm{CL}+\mathrm{CR}+\mathrm{SG})$, Compliment+ Suggestion+ Reason $(\mathrm{CL}+\mathrm{SG}+\mathrm{RN})$, and Criticism/Suggestion+ Compliment (CR/SG+ CL).

Regarding the first strategic option, $40 \%$ of the reviewers pair a positive appraisal with a specific criticism in order to strike a kind of balance between negative and positive appraisal (Example (18)).

(18) jaa?a al-faSl-u l-3awal-u muqadimat-an taiybat-an (Compliment) wa-laakin tafarradat basdah-u l-fuSuul-u faaqidat-an tasalsulahaa wa-taraabutahaa (Criticism)

'The first chapter was a good introduction (compliment), but the chapters following it lack cohesion and connectedness' (Criticism). 
The second strategy, which is employed by $18 \%$ of the reviewers, involves a compliment followed by a string of criticisms and suggestions $(\mathrm{CL}+\mathrm{CR}+\mathrm{SG})$ as is shown in Example (19).

(19) Pal-muRalif-u mutamakin-un Pilaa had-in kabiir-in fii tanwiis-i al-maSaadir (Compliment) Rillaa ?annah-u Rahyaanan laa yarjis-u Rila al-maSdar-i l-2aSlii (Criticism). wa-kaan-a min al-3afDal-i Pan yufiir-a Rila al-maSdar-i l-2aSlii (Suggestion)

'The author is proficient to a great extent in varying his resources (Compliment), but sometimes he does not consult the original reference (Criticism). It would have been better to refer to primary sources' (Suggestion).

The third strategic option is pairing a compliment with a suggestion followed by a reason in order to provide a sound argumentation for the reasonableness of the effect of the suggestion. Reviewers opt for this strategy in $22 \%$ of the negative appraisals (Example (20)).

(20) laqad aSaab-a al-kaatib-u bi-xtiyaar-i haaða al-mawDuus (Compliment) wa-laakin kaan-a bi-Timkaanih-i Pan yastatrid-a bimawDuusaatih-i (Suggestion) li-Pahamiyatihaa (Reason)

'The author was accurate in the choice of the subject (Compliment), but he could have elaborated on its topics (Suggestions) because of their importance' (Reason).

The fourth option (20\%) is providing a compliment immediately after a suggestion or a criticism $(\mathrm{CR} / \mathrm{SG}+\mathrm{CL})$ in order to soften the effect of the negative acts and maintain rapport.

(21) Tixtatam-a l-mu?alif-u kitaabah-u bi-SarD-i simaat-i wa-majaakil-i l-Ridaarah... Pillaa Panna mawqis-a haaðih-i i-simaat-i fii nihaayat-i l-faSl-i lam yakun munaasib-an (Criticism)... silman Panna al-mu?alif-a haafaD-a salaa tasalsul-i l-2afkaari wa-taraabutihaa munð-u l-bidaayah (Compliment)

'The author concluded his book by presenting the features and problems of management. However, inserting these features at the end was not suitable (Criticism) despite the fact that the author maintained the sequence and coherence of these ideas from the beginning' (Compliment)

\subsection{Closing}

This move has the purpose of closing the text, providing a recommendation or a final evaluation. The reviewers, in the final paragraph tend to use metadiscoursal markers indicating termination such as $f$ - l-xaatimah (Example (23)), wa- $f i$ il-xitaam (Example (25)) (meaning 'at the end', 'in conclusion') to signal that the 
text is about to end, or an explicit invitation to read the book, like ?adsuu 'invite' (Example (22)), or a conjunctive adjunct indicating a conclusion, which is sometimes followed by an explicit lexeme carrying a future wish (e.g. liðaa natamanaa 'therefore we wish', Example (24)).

Thirty four percent of the reviews end with a step definitely recommending the book focusing on its usefulness to the prospective readership or its value to the discipline (Example (22)).

(22) Inaa ?adsuu kull-a baahit-in sarabiyy-in ?an yaqr?a haaðih-i i-dirraasat-i likay yusiid-a tafkii-a aSSuurat-i san il-maaDii wa-l-haaDir.... yustabar-u l-kitaab-u 3iDaafat-an bihaq lil-makatabat-i l-sarabiyyah

'I invite every Arab researcher to read this study in order to reformulate the picture about the past and the present. ... The book is really a significant contribution to the Arabic library.'

The second type of closings is recommending that the book be worth reading despite its shortcomings (18\%). Reviewers generally use the discourse markers of totality such as $f$ - l-xaatimah together with adversative conjunctions like sala ar-raym-i min (in spite of, although) to end this move (Example (23)).

(23) fi-l-xaatimah, sala ar-raym-i min haaðih-i l-mulaahaDaat-i wa-tasliiqaat, fa-haaða al-kitaabu marjis-un qaiym-un lit-tarbawiin-a fii haaða al-majaal 'At the end, in spite of all these comments and notes, this book is a valuable reference for educators in this field.'

In $24 \%$ of the BRs, the final section closes with a neutral summary (Sub-move 3) highlighting the general aspects of the book. The fourth type of closings (12\%) is a kind of encouragement to inspire authors to produce further similar books (Example (24)), whereas the fifth (12\%) is a sort of supplication invoking God's (Allah) favors upon the reviewee to bless him/her and bring him/her more success (Example (25)).

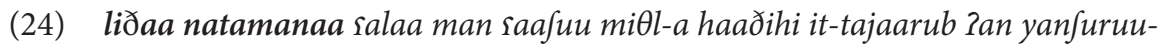
haa li?annhaa satakuun-u maSaadira fi fu?uuninaa min wijahat-i naðar-in sarabiyyah...walaa yarawa Panna al-kutaab-a al-sarab ladiyhim-u al-maqdirat-i wal-kafaa?at-i salaa mutaabsat-i ðaalik li-tahqiiq-i haaða al-hadaf

'Therefore, we wish that those who had undergone such experiences publish them because they will be a source of reference in our affairs from an Arabic perspective. And there is no doubt that Arab authors have the ability and proficiency to pursue this and fulfill this aim.'

(25) wa-fi il-xitaam ras?al-u al-laah-a al-saliyy il-sadiim ?an yujzil-a lihaaða al-kaatib ?al-2ajr-a al- sadiim

'In conclusion, I supplicate to Allah the Glorious and Almighty to endow this writer with numerous and countless bounties...' 


\section{Discussion}

In the present study, I have adopted a genre-pragmatic analysis to identify the generic components of ArBRs in order to find out to what extent these components fulfill the communicative informative and evaluative purposes of a peer's newly published book. The study has revealed that there are four strategic moves (i.e. Introducing the book, Describing the book, Evaluating the book, and Closing) by means of which the BRs are structured (see Table 1). The component structure of ArBRs was found to be quite similar to that found by other researchers in English (e.g., Motta-Roth 1998) though there are differences in the frequency and type of sub-moves employed.

The results of pragmatic functional analysis provide evidence that the major function of ArBRs is descriptive-informative, whereas the pragmatic evaluative function is minor. What elucidates the former function is the frequent use of descriptive sub-moves which is statistically evident in 'Stating the general purpose' (84\%), and 'Providing a summary of each chapter or of the general topic' (80\%). Besides, almost half of the ArBRs (i.e. 48\%) are uncritical; they only present a neutral detailed description of the book, without giving any personal opinion or evaluative comments with regard to its contents (see Table 1). That is to say, what matters for Arab reviewers is to tell the readers about the content of the book reviewed; such a conclusion lends support to Al-Ali and Sahawneh's $(2011,30)$ findings that Arab writers focus on telling. Unlike the previous studies reviewed, which consider evaluation the backbone of the BRs, the ArBRs' main purpose is to fulfill the transactional function (Brown and Yule 1983) rather than the interpersonal-evaluative function of language, though the latter should be taken seriously in the reviewing process.

Regarding the pragmatic evaluative function, these reviews include 434 appraisal statements with an average of 8.5 cases per review. The reviewers tend to avoid criticism and to make frequent use of praise instead. For example, the positive evaluation is not only more frequent $(76.5 \%)$ but also significantly exceeds negative acts (23.5\%). However, such results differ from those of previous studies, which indicate that English BRs display both positive and negative evaluative acts, almost to a similar level (Hyland 2000; Lores-Sanz 2012). This very low occurrence of criticism in Arabic reviews might be attributed to Arab reviewers' cultural expectations in that they tend to be sympathetic in their appraisal in order to maintain a respectful and harmonious atmosphere with their peer reviewees. What supports this tendency is the fact that their use of negative evaluation acts is kept to the minimum though it is considered a significant feature of this genre. Moreover, Arab reviewers appear to demonstrate sensitivity to their colleagues' works and probably avoid strong reactions. Even when they criticize, they generally qualify their criticism with a hedging tone 'to make their texts look safer' (Motta-Roth 1998: 44). They tend to compensate for the negative critical tone by surrounding 
the negative criticism or suggestion with positive evaluative strategies including the following: compliment-criticism/suggestion and/or criticism-reason pairing in order to attenuate the possible threat to the reviewee's negative face.

What further supports the dearth of critical spirit in ArBRs is the frequency and distribution of criticism among the qualities of the book evaluated. Regarding the qualities related to the author and the readership, Arab writers opt only for praise to evaluate these qualities, whereas criticism is nonexistent. Even when the content and style are negatively evaluated, Arab reviewers criticize the very minor aspects of these qualities. Such tendencies reflect the lack of critical spirit in the ArBRs, especially the author of the book. This propensity differs a lot from what has been reported in the BBRs which reflect a sense of balance between criticism and praise, on the one hand, and a balance of the weight given to the qualities evaluated, on the other. The dearth of criticism in most of the BRs analyzed reflects a predisposition of avoidance on the part of Arab reviewers of criticism of a peer's work.

With respect to genre analysis, I identified sub-moves that have only been used by Arab reviewers and have not been reported in the former studies (e.g., 'Instantiating further similar research', 'Making supplications for the author' and 'Providing a summary of each chapter or of the general topic'). These additional sub-moves can be thought of as culture or language bound and can to be explained with reference to the socio-cultural and academic context in which these texts are anchored. The use of 'Instantiating further similar research' by ABRs echoes a sense of encouragement that may create a kind of motivation in the part of the prospective readers (Al-Ali 2005) to produce further similar works. With regard to the second sub-move, it contains supplications invoking God's (Allah) favors upon the authors of the books to reward them, bless their knowledge and help them achieve success in their future research. Such a behavior can be explained with reference to Muslim's belief that God (Allah) is thought of as the source of bless, reward and inspiration. According to Morrow (2006: 138), the greatest way to thank people in Islam is to call upon Allah to bless and reward them. Therefore, this culture specific option supports Al-Ali's (2010) claim that religious and socio-cultural affiliations are at work in the writing of a particular genre and thus impinge on the writers' preferences and practices. Regarding the third sub-move that BRs are just neutral summaries of the content, this indicates that Arab book reviewers have assigned weight different of that assigned by English reviewers to the informative and evaluative goals of the reviews. Therefore, one can say that reviewers are embedded in a socio-cultural and academic context from which they make their rhetorical options in order to articulate their communicative purpose. Based on this conclusion, one can argue that Arab reviewers have a different understanding of the main communicative purpose of the BRs. Thus, they have not succeeded to fulfill the most substantial aim stated in the former studies: the appraisal of new knowledge. 


\section{Concluding remarks}

In the present study, I have adopted a genre and pragmatic analysis to identify the component moves and evaluation options employed to articulate the communicative purposes of ArBRs in academic journals. Our analysis reveal that Arab reviewers tend to avoid assessing other's works negatively to the extent that criticism does not exist in half of the ArBRs though critical evaluation is the backbone of this genre. Instead, most of the book reviewers clearly and purposively favor giving information; such a rhetorical tendency seems to be a significant feature of ArBRs. By contrast, criticism is of intrinsic significance to the interpersonal aspect of BBRs. Therefore, Arab reviewers should attend to the critical spirit of this genre because science would not advance 'without refutation, criticism, dissension [and] disagreement' (Salager-Meyer et al. 2007, 1761).

The conclusion to be drawn is that the goal of the academic community within which these texts have been produced has given rise and weight to the descriptiveinformative purpose of ArBRs. This is because the communicative purpose of genre, in general, is usually a response to the relationship among the interlocutors, on the one hand, and the writing culture that constrains academic preferences, on the other.

Regarding the additional component sub-moves that do not surface in the English BRs and the finding that ABRs are more prone to book summarizing instead of evaluating, one possible explanation is that Arab reviewers, in contrast to English, may have not developed established schemata for book reviewing. This may be due to the long-standing tradition of the formal teaching of all aspects of writing in the British educational systems and the publications of style manuals related to genre writing (Salager-Meyer et al. 2003). By contrast, such teaching has never been a tradition in Arab countries, where students are expected to master such genres through self-teaching. It is also worthwhile mentioning that ArBRs started to surface in academic journals only recently in comparison to the widespread and well-established English BR, which is back dated to the introduction of The Edinburgh Medical Journal in 1802 and the Physical Review Journal in 1893 (Hyland 2000).

Therefore, it is recommended that students, as aspiring researchers, be familiarized at early university level with the generic elements and the necessary knowledge of the evaluative nature of this genre in order to 'develop their critical thinking and express their judgments in a socially appropriate manner' (Gea Valor 2000, 87). Furthermore, it would also be more beneficial to teach students the conventions and preferred styles of book reviewing in their fields (Stotesbury 2003: 340) rather than teaching them the generic conventions and commonalities suggested by guidelines for all disciplines.

It is worthwhile saying that this study analyzed a corpus drawn from different disciplines in humanities and social sciences; therefore, its findings cannot be 
generalized to each individual discipline. Further, it would be very relevant to follow up this research with further quantitative and qualitative studies comprising extensive samples drawn from different disciplines to find out to what extent writing practices in each discipline affect the way 'book review writers approach' each discipline.

\section{Acknowledgements}

The research reported in this article was funded by Jordan University of Science and Technology. The researcher is thankful to the two anonymous reviewers of this article and the editorial board of this journal.

\section{Transliteration}

The most noteworthy symbols used in transcribing Arabic words given in this article are: 1 glottal stop, q voiceless uvular stop, g voiced velar stop, d emphatic voiced alveolar stop, $\partial$ emphatic voiced alveolar fricative, $\partial$ voiced interdental fricative, $\theta$ voiceless interdental fricative, $j$ voiced post-alveolar affricate, y palatal glide, $\int$ voiceless alveolar fricative $t$ voiced dental emphatic stop, $s$ voiceless alveolar fricative, $h$ voiceless glottal fricative, $S$ voiceless alveolar emphatic fricative, $D$ voiced alveolar emphatic stop, $\hbar$ voiceless pharyngeal fricative, $x$ voiceless uvular fricative, $y$ voiced uvular fricative, $\{$ voiced pharyngeal fricative, a short central low vowel, aa long central low vowel, u short back high vowel, uu long back high vowel, i short front high vowel, and ii long front high vowel.

\section{References}

Al-Ali, M. 2005. "Communicating Messages of Solidarity, Promotion, and Pride in Death Announcements Genre in Jordanian Newspapers." Discourse and Society 16: 5-31. doi: $10.1177 / 0957926505048228$

Al-Ali, M. 2010. "Generic Patterns and Socio-Cultural Resources in Acknowledgements Accompanying Ph.D. Dissertations." Pragmatics 20 (1): 1-26. doi:10.1075/prag.20.1.01ali

Al-Ali, M., and Y. Sahawneh. 2011. "Rhetorical and Textual Organization of English and Arabic Ph.D. Dissertation Abstracts in Linguistics." SKY Journal of Linguistics 24: 7-39.

Alcaraz-Ariza, M. 2010. “Evaluation in English Medium Medical Book Reviews.” International Journal of English Studies 2 (1): 137-153.

Belcher, D. 1995. “Writing Critically across Curriculum." In Academic Writing in a Second Language: Essays on Research and Pedagogy, ed. by D. Belcher, and D. Braine, 135-155. Norwood, NY: Ablex.

Bhatia, V. 1993. Analyzing Genre: Language Use in Professional Settings. London: Longman.

Bhatia, V. 2004. Worlds of Written Discourse. London: Continuum. 
Brown, P., and S. Levinson. 1987. Politeness: Some Universals in Language Use. Cambridge: Cambridge University Press.

Brown, G., and G. Yule. 1983. Discourse Analysis. Cambridge: Cambridge University Press. doi: $10.1017 / C B O 9780511805226$

Felber, L. 2002. "The Book Review: Scholarly and Editorial Responsibility." Journal of Scholarly Publication 33 (3): 166-172. doi:10.3138/jsp.33.3.166

Gea Valor, M. 2000. A Pragmatic Approach to Politeness and Modality in the Book Review Articles. SELL Monograph. Valencia: Universitat Valencia.

Gea Valor, M. 2000-2001. "The Coding of Linguistic Politeness in the Academic Book Reviews." Pragmalinguistica 8-9: 165-178.

Gea-Valor, M. 2014. “From 'Readers may be left wondering' to 'I’m genuinely puzzled': The Construction of Self and Others in Fiction Book Reviews." In Dialogicity in Written Specialised Genres, ed. by L. Gil-Salom, and C. Soler-Monreal, 113-134. Amsterdam: John Benjamins. doi: 10.1075/ds.23.06gea

Halliday, M. 1994. An introduction to Functional Grammar (2nd ed.). London \& New York: Routledge.

Hartley, J. 2006. "Reading a Writing Book Reviews across Disciplines." Journal of the American Society for Information Science and Technology 57 (9): 1194-1207. doi:10.1002/asi.20399

Hunston, S. 1993. "Evaluation and Ideology in Scientific Writing." In Register Analysis: Theory and Practice, ed. by M. Ghadessy, 57-73. London: Pinter.

Hunston, S. 1994. "Evaluation and Organization in a Sample of Written Academic Discourse." In Advances in Written Text Analysis, ed. by M. Coulthard, 191-218. London: Routledge.

Hyland, K. 2000. Disciplinary Discourses. Social Interactions in Academic Writing. Harlow: Pearson Education.

Itakura, H., and A. Tsui. 2011. "Evaluation in Academic Discourse: Managing Criticism in Japanese and English Book Reviews." Journal of Pragmatics 43: 1366-1379.

doi: 10.1016/j.pragma.2010.10.023

Johnson, D. 1992. "Compliments and Politeness in Peer-review Texts." Applied Linguistics 13 (1): 51-71. doi:10.1093/applin/13.1.51

Johnson, D., and D. Roen. 1992. "Complimenting and Involvement in Peer Reviews: Gender Variation.” Language and Society 21: 27-57. doi:10.1017/So047404500015025

Lores-Sanz, R. 2012. "Local Disciplines, Local Cultures: Praise and Criticism in British and Spanish History Reviews." Brno Studies in English 38 (2): 97-116. doi:10.5817/BSE2012-2-6

Lindholm-Romantschuk, Y. 1998. Scholarly Book Reviewing in the Social Sciences and Humanities: The Flow of Ideas within and amongst Disciplines. Westport, CT: Greenwood Press.

Martin, J., and P. White. 2005. The Language of Evaluation. Appraisal in English. Houndmills, UK: Palgrave Macmillan.

Morrow, J. 2006. “The Origin of the Allah Lexicon." In Arabic, Islam, and the Allah Lexicon, ed. by J. Morrow, 115-187. New York: Edwin Mellen Press.

Moreno, A., and L. Suarez. 2008a. "A Study of Critical Attitude across English and Spanish Academic Book Reviews." Journal of English for Academic Purposes 7: 15-26. doi:10.1016/j.jeap.2008.02.009

Moreno, A., and L. Suarez. 2008b. "A Framework for Comparing Evaluation Resources across Academic Texts." Text and Talk 28 (6): 749-769. doi:10.1515/TEXT.2008.038 
Moreno, A., and L. Suarez. 2009. "Academic Book Reviews in English and Spanish: Critical Comments and Rhetorical Structure." In Academic Evaluation: Review Genres in University Settings, ed. by K. Hyland, and D. Giuliana, 161-178. Basingstoke: Palgrave Macmillan.

Motta-Roth, D. 1998. "Discourse Analysis and Academic Book Reviews: A Study of Text and Disciplinary Cultures." In Genre Studies in English for Academic Purposes, ed. by I. Fortanet, S. Posteguillo, J. C. Palmer, and J. Coll, 29-559. Colleccio Summa, Seri Filolgia 9. Castellón: Universitat Jaume I.

Nicolaisen, J. 2002. "Structure-based Interpretation of Scholarly Book Reviews: A New Research Technique." In Emerging Frameworks and Methods: Proceedings of the 4th International Conference on Conceptions of Library and Information Science, ed. by H. Bruce, R. Fidel, P. Ingwersen, and P. Vakkari, 123-135. Westport, CT: Libraries Unlimited.

Salager-Meyer, F., and M. Alcaraz-Ariza. 2004. "Negative Appraisals in Academic Book Reviews; A Cross-Linguistic Approach." In International Aspects of Specialized Communication, ed. by C. Candlin, and M. Gotti, 149-172. Bern: Peter Lang.

Salager-Meyer, F., M. Angeles, A. Ariza, and N. Zambrano. 2003. “The Scimitar, the Dagger and the Glove: Intercultural Differences in the Rhetoric of Criticism in Spanish, French and English Medical Discourse (1930-1995)." English for Specific Purposes 22 (3): 223-247. doi:10.1016/So889-4906(02)00019-4

Salager-Meyer, F., M. Angeles, A. Ariza, and M. Berbesi. 2007. "Collegiality, Critique and the Construction of Scientific Argumentation in Medical Book Reviews: A Diachronic Approach." Journal of Pragmatics 39: 1758-1774. doi:10.1016/j.pragma.2006.06.003

Stotesbury, H. 2003. "Evaluation in Research Article Abstracts in the Narrative and Hard Sciences." Journal of English for Academic Purposes 2: 327-342. doi:10.1016/S1475-1585(03)0oo49-3

Suárez, T., and A. Moreno. 2008. "The Rhetorical Structure of Academic Book Reviews of Literature: An English-Spanish Cross-Linguistic Approach.” In Contrastive Rhetoric: Reaching to Intercultural Rhetoric, ed. by U. Connor, E. Nagelhout, and W. Rozycki, 147-168. Amsterdam, Philadelphia: John Benjamin Publishing Company. doi:10.1075/pbns.169.10sua

Swales, J. 1990. Genre Analysis: English in Academic and Research Settings. Cambridge University Press, Cambridge.

Thetela, P. 1997. "Evaluated Entities and Parameters of Value in Academic Research Articles." English for Specific Purposes 16 (2): 101-118. doi:10.1016/So889-4906(96)00022-1

Thompson, G., and S. Hunston. 2000. "Evaluation: An Introduction." In Evaluation in Text, ed. by S. Hunston, and G. Thompson, 1-27. Oxford: Oxford University press.

Vandenbroucke, J., and A. de Craen. 2001. "Alternative Medicine: A "Mirror Image" for Scientific Reasoning in Conventional Medicine.” Annals of Internal Medicine 135: 507-513.

doi: 10.7326/0003-4819-135-7-200110020-00010 


\section{Appendix}

List of Arabic journals from which the sample of the texts was drawn:

$$
\begin{aligned}
& \text { مجلة جامعة الملك عبد العزيز. } \\
& \text { المجلة التربوية / جامعة الكويت. } \\
& \text { مجلة جامعة دمشق. } \\
& \text { مجلة كلية الآداب/ جامعة الرياض. مجاض. } \\
& \text { مجلة جامعة ام القرى للعلوم التربوية والاجتماعية والانسانية. }
\end{aligned}
$$

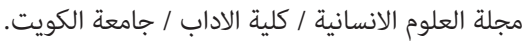

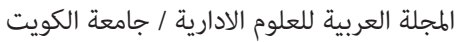

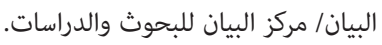

$$
\begin{aligned}
& \text { دراسات الخليج والجزية العربية }
\end{aligned}
$$

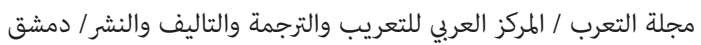

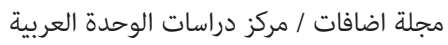

$$
\begin{aligned}
& \text { مجلة المستقبل العربي } \\
& \text { مجلة دراسات شرق اوسطية }
\end{aligned}
$$

\section{Author's address}

Mohammed Nahar Al-Ali

Jordan University of Science and Technology, Irbid

Jordan

alali@just.edu.jo 
